\title{
26 THE INUSIBLE HAND: Governmental Influences on the Field of Play During the Production and Diffusion of Mobile TV
}

\author{
Su-Yi Lin \\ Mike W. Chiasson \\ University of Lancaster \\ Lancaster, UK
}

\begin{abstract}
The purpose of this paper is to examine how government agencies alter the context around the production and diffusion of technologies, and how this strengthens or weakens particular ICT trajectories. An embedded case is conducted to address this question in Taiwan, as governmental actions affected the early production and diffusion of DVB-H technology and WiMAX technology, both of which enable mobile TV services. The context around and across these two technologies are analyzed from an institutional perspective, including the framework proposed by King et al (1994). The key lesson of this paper is that government agencies are capable of influencing the diffusion of nomadic technologies through their legitimating powers, specific national policies, the allocation of radio frequency spectrum, the implementation of regulations, and the allocation of financial resources. However, the ultimate effects are determined by mixed institutional factors and sometimes contradictory governmental interventions, stemming from historical differences and conflicts across the various government agencies involved. The implications for ICT diffusion research and governmental policy makers are discussed.
\end{abstract}

Keywords Diffusion, institutional theory, wireless broadband technology, mobile TV

\section{INTRODUCTION}

Internet and mobile communication technologies have ushered in a new era of various ICT-based innovations and resulting social phenomena. For example, communi-

Please use the following format when citing this chapter:

Lin, S-Y., and Chiasson, M. W., 2008, in IFIP International Federation for Information Processing, Volume 287, Open IT-Based Innovation: Moving Towards Cooperative IT Transfer and Knowledge Diffusion, eds. León, G., Bernardos, A., Casar, J., Kautz, K., and DeGross, J. (Boston: Springer), pp. 461-481. 
cation and office technologies purportedly allow telecommuters to work from anywhere, and advanced wireless broadband technologies are claimed to allow mobile TV viewers to watch digital content from any location, through wireless handsets. Lyytinen and Yoo (2002) have called this socio-technical effect the nomadic information environment:

A heterogeneous assemblage of interconnected technological and organizational elements that enable the physical and social mobility of computing and communication services between organizational actors both within and across organizational borders (p. 378).

To study the development, implementation, and impact of ICT, information systems researchers have increasingly paid attention not only to ICT itself, but to the social and political context around ICT (Kling and Scacchi 1982; Markus and Robey 1988). This focus on context has lead IS researchers to study how context affects technological trajectories, including nomadic technologies, and how context is affected by the development of such technologies (Allen and Wilson 2005; Henfridsson and Lindgren 2005; Lin and Chiasson 2007; Lyytinen and Rose 2003; Tilson et al. 2006).

The complexity and pace of ICT now affects many organizations and government agencies, resulting in a shifting and complicated context around ICT-based innovation. This is particularly the case with nomadic technologies since governments generally see them as a vital means of increasing their international competitiveness, and so they have become important players and interventionists in fostering the production and diffusion of nomadic technologies. Their roles include policy makers, market accelerators, competitive environmental creators, and regime regulators (Sawyer et al. 2003). Theoretically, governments can be regarded as part of the infrastructures for the rise and continuance of nomadic technologies at the interorganizational level. The eighth theme in Lyytinen and Yoo's paper highlights such a key question in IS research: how do government agencies, policies, and actions affect the context and resulting field-of-play in developing ICT-based industries, including the effect on ICT groups and technological trajectories? In our case, we focus specifically on mobile interorganizational services.

A number of researchers have studied governmental roles and policies relating to the production and diffusion of ICT in general (Avgerou 2000; King et al. 1994; Montealegre 1999) and in nomadic computing specifically (Andersen et al. 2003; Choudrie and Lee 2004; Ishii 2004; Lee et al. 2003). However, most researchers focus on the diffusion of an innovation after it is well developed and diffusing. Little attention is paid to how governments intervene and affect the development of new ICT and the formation of new industries during the very early stages, particularly their effects on the institutional fieldof-play and the trajectories of these early technical groups. Consequently, the research questions addressed in this paper are (1) how do governments intervene in the diffusion of ICT, and (2) how do the governments and their interventions affect the field-of-play and industrial setting during the initiation and early diffusion of ICT? According to Orlikowski and Barley's (2001) suggestion,

An institutional perspective would offer IT researchers a vantage point for conceptualizing the digital economy as an emergent, evolving, embedded, fragmented, and provisional social production that is shaped as much by cultural and structural forces as by technical and economic ones (p. 154). 
The remainder of this paper is structured as follows: First, institutional theory is briefly reviewed in order to identify key concepts used in this paper. We then explain our research methodology, which examines the comparative effect of the government on two emerging wireless broadband technologies in Taiwan. The next two sections present our findings and discussion using an institutional perspective. The paper concludes with suggestions for practice and further research. To our knowledge, this is the first empirical study focusing on how governments affect the initiation and early diffusion of nomadic technologies. The key lesson of this paper is that government agencies are capable of influencing ICT diffusion through their legitimating powers, specific national policies, the allocation of radio spectrum, the implementation of regulations, and the allocation of financial resources. However, the ultimate effects of varying or contradictory governmental influences, stemming from historical conflicts and separations across the various agencies involved, produce a complicated and shifting field-of-play for industrial participants, and a number of surprises due to complex institutional forces.

\section{INSTITUTIONAL THEORY}

In general, an institution is regarded as "any standing social entity that exerts influence and regulation over other social entities" (King et al. 1994, p. 148), for example, governments, universities, churches, trade and industry associations, as well as international agencies (e.g., United Nations). Institutional theorists consider institutions to be various contextual factors that rationalize a set of actions over time and space, through not only economic efficiency but also cultural, political, and socio-technical actions. A more precise definition of institutions is given by Scott (1995):

Institutions consist of cognitive, normative, and regulative structures and activities that provide stability and meaning to social behavior. Institutions are transported by various carriers - culture, structures, and routines - and they operate at multiple levels of jurisdiction (p. 33).

Numerous studies have paid attention to the legitimacy basis for action and the mechanisms involved in the three institutional elements: regulative, normative, and cognitive. The interweaving process of the institutional elements, called institutionalization, can be top-down or bottom-up. While early sociologists focus on how existing cultural and structural patterns form institutions through top-down influences, late sociologists and organizational scholars observe that some institutions are driven by entrepreneurs or internal managerial participants through bottom-up creation (Scott 1995).

Extending from sociology and organizational studies, institutional theory has been applied to the IS field for decades, including ICT diffusion research (Avgerou 2000; King et al. 1994; Montealegre 1999; Swanson and Ramiller 1997; Teo et al. 2003). Since most IS research focuses on macro-analysis of institutions or how institutional elements are imposed upon or upheld within or across organizations, only a few studies combine the general and theoretical definitions of institutions to examine how governments, industry associations, or international agencies influence ICT diffusion (Andersen et al. 2003; Choudrie and Lee 2004; Damsgaard and Lyytinen 2001; Damsgaard and Scheepers 1999; 
Table 1. Dimensions of Institutional Intervention Proposed by King et al. (Adapted with permission from J. L. King, V. Gurbaxani, K. L. Kraemer, F. W. McFarlan, K. S. Raman, and C. S. Yap, "Institutional Factors in Information Technology Innovation," Information Systems Research (5:2), 1994, p. 151. Copyright (C) 1994, The Institute for Operations Research and Management Sciences, 7240 Parkway Drive, Suite 210, Hanover, Maryland 21076.)

\begin{tabular}{|c|c|c|c|}
\hline & Supply-Push & & Demand-Pull \\
\hline \multirow[t]{2}{*}{ Influence } & \multicolumn{2}{|l|}{$\begin{array}{l}\text { (1) Knowledge Building } \\
2 \text { Knowledge Deployment } \\
3 \text { Subsidy } \\
\text { (6 Innovation Directive }\end{array}$} & $\begin{array}{l}2 \text { Knowledge Deployment } \\
3 \text { Subsidy } \\
\text { (4 Mobilization }\end{array}$ \\
\hline & & I & II \\
\hline \multirow[b]{2}{*}{ Regulation } & & III & IV \\
\hline & \multicolumn{2}{|l|}{$\begin{array}{l}(2 \text { Knowledge Deployment } \\
\text { (3) Subsidy } \\
\text { 5 Standard setting } \\
\text { 6 Innovation Directive }\end{array}$} & $\begin{array}{l}\text { (3) Subsidy } \\
\text { 5 Standard setting } \\
6 \text { Innovation Directive }\end{array}$ \\
\hline
\end{tabular}

Ishii 2004; Lee et al. 2003; Miscione 2007; Silva and Figueroa 2002). An analytical framework proposed by King et al. (1994) is often used for examining how and to what extent the institutions intervene in ICT diffusion.

Table 1 shows King et al.'s framework classifying institutional interventions into four cells represented by Roman numerals I through IV, according to the strength of initiatives and the type of driving forces. Institutional forces can invoke soft persuasion as the influence or hard coercion as the regulation. Innovation can be driven by supplypush or demand-pull. Demand-pull emerges from the provision of resources to support organizational preferences while supply-push is based on providing and "pushing" services into organizations. Six complementary institutional interventions - knowledge building, knowledge deployment, subsidy, mobilization, standard setting, and innovative directive - are then put into the two-dimensional matrix.

Relating this to our study, we apply the description of each institutional intervention in the context of governmental intervention in the diffusion of nomadic technologies as follows:

- Knowledge building, in the influence and supply-push dimension (I), aims to support research and development activities in order to produce the basic knowledge of nomadic technologies and foster the understanding and localization of suppliers. For example, a governmental research project focused on how to maintain reliable data transmission to fast moving users would fall into this category.

- Knowledge deployment indicates the distribution of key concepts and techniques through education or training led or funded by governments. Interventions such as optional courses on mobile TV production at universities are classified into the influence and demand-pull dimension (II) if the main objective is to boost users' adoption. Interventions such as professional seminars or certificate tests of employees in the mobile TV industry are classified into dimension I or III if the main objective is to enrich suppliers' R\&D knowledge. 
- Subsidy describes the "institutional activities designed to produce specific innovative outcomes" (King et al. 1994, p. 154). It includes, but is not limited to, the direct or indirect governmental financial support for technical trials (I) and facility procurement (II), tax deduction (III), and governmental sponsorship (IV) for using particular types of nomadic technologies.

- Mobilization is an encouragement of the "best choice" favored by governments, through awareness campaigns, workshops, seminars, conferences, and other promotional activities (II) such as the announcement of national policies and related media reports.

- Standard setting produces boundaries that limit actors' choices. This powerful intervention could be a set of regulations for governing the suppliers (III) or a technical protocol endorsed by governments for stimulating particular innovations (IV).

- Innovation directive is a command for the production or adoption of specific nomadic technologies such as e- or m-government applications using particular technologies (I), an investment requirement for particular technologies (III), or an administrative order for using particular technologies (IV).

In this paper, we use an institutional view including King et al.'s framework to analyze our data in order to answer the research question. Detailed illustrations are provided in our findings and discussions.

\section{RESEARCH METHODOLOGY}

An embedded single-case study design is used in this paper to trace how the Taiwanese government affected the early diffusion of two wireless broadband technologies before the end of 2007. In Yin's (1984) research, an embedded case includes multiple units of analysis, so it is particularly applicable to multilevel analysis, which is important in institutional theoretical studies. We can simultaneously understand the effect of governmental background, policy, and intervention (at one level) on the wireless broadband technology development in two industrial clusters (another level) within the same setting. The two clusters driven by digital video broadcasting-handheld (DVB-H) technology and worldwide interoperability for microwave access (WiMAX) technology are selected because both of the technologies enable mobile TV services and have been frequently compared by every stakeholder, including government agencies, in Taiwan. As an official document states

The research on the emerging issues, like the competition and collaboration in the spectrum demand between WiMAX technology and Digital TV (including DVB-H technology), should be increased in the future (National Science Council 2006, p. 14).

The case study data were collected from three sources. First, the first author worked in the Institute for Information Industry, a governmental think tank and management 
consultancy in Taiwan, for five years. She was involved in a WiMAX project authorized by the Taiwanese government from July to September 2005, including 15 interviews with ICT industrial participants and numerous meetings with the government officials as well as a consultant team. This experience assisted us in closely understanding the working logic of Taiwanese government agencies, how WiMAX technology followed the governmental plan and acquired legitimacy, and how a WiMAX cluster composed of ICT industrial actors was created over time. The second source of our data is a fieldwork for a broader mobile TV research conducted by the first author in Taiwan from January to September 2007. The forming and reshaping of DVB-H cluster was investigated through participant observation and 27 interviews with government agencies and participants in ICT and media industries. Key participants' talks and behaviors were analyzed in order to understand the context around the interplay between the government and industries in the early diffusion of mobile TV. The final data source comes from the documentary evidence, including field notes, project records, online documents, other first-hand data from interviewees or public conferences, and second-hand data from governmental publications or media reports. The documentary evidence supplied details to our case study. In summary, the data provides a rich base to compare and analyze how various Taiwanese government agencies affect the diffusion of the DVB-H and WiMAX technologies.

\section{FIELD OF INSTITUTIONAL PLAY}

To represent the institutional field-of-play during the initial development of mobile TV in Taiwan, we explain the concepts of the two wireless broadband technologies first. We then interpret the governmental background, including the political relations among key government agencies. Finally, King et al.'s framework is used to analyze governmental interventions in the initiation and early diffusion of DVB-H and WiMAX technologies respectively.

\subsection{DVB-H and WiMAX Technologies}

The technical principles and industrial strategies of DVB-H technology versus WiMAX technology are very different. DVB-H technology is a branch of digital TV technology, particularly designed for mobile TV services. One of the largest mobile handset manufacturers, Nokia, is its primary promoter. With a broadcasting format to send signals in a one-to-many manner, DVB-H technology can support digital content to be concurrently downloaded to millions of DVB-H mobile handsets as long as the handsets are within the digital signal coverage. However, it does not support two-way communication, as existing and future mobile phone systems do. Terrestrial TV stations in Taiwan, which own broadcasting networks and TV content producing teams, have included the adoption of DVB-H technology in their business plans since 2005 because the Taiwanese government declares that TV signals will be converted into digital code by 2012. Their hope is that they can enter the mobile service market and escape from 
their declining TV advertising market by adding DVB-H transmitters on their existing broadcasting towers, along with some technical facilities and support.

In contrast, WiMAX technology, regarded as a fourth generation (4G) technologythe next-generation of $3 \mathrm{G}$ - provides one-to-one, two-way, high speed, and wide broadband access. Since 2004, before the WiMAX standards were finalized by the WiMAX Forum, two WiMAX technical standards-IEEE 802.16d and 802.16e- had been promoted in Taiwan by the ICT industry giant Intel. While $802.16 \mathrm{~d}$ supports fixed and portable wireless broadband access to laptops, 802.16e supports mobile wireless broadband access to handsets. Given Intel's lobbying of the Taiwanese government and the ambition of the Taiwanese ICT industry to take part in setting an international standard at an early stage, the majority of government agencies and industry participants in Taiwan were convinced that WiMAX technology had a great market potential, especially for Internet protocol (IP) phone and mobile video services. In contrast with the $802.16 \mathrm{~d}$ standard, 802.16e acquired increasing attention because the other fixed or portable wireless broadband solutions (e.g., ADSL, Cable Modem, and Wi-Fi) had been widely used in homes, offices, and cafés in Taiwan. Six WiMAX commercial licenses were issued in late 2007.

From a technological perspective, DVB-H and WiMAX technologies belong to the broadcasting industry and the telecommunication industry respectively. However, their advantages and disadvantages in delivering mobile TV, like the numbers of concurrent users and the interactive functions, have resulted in their competing with each other. This highlights that the technology cannot be considered independent from its context, including the institutions produced by government agencies.

\subsection{Governmental Background}

Taiwan has invested heavily in the ICT infrastructure and has incubated the ICT industry since the 1970s. The fruitful result is that Taiwan has become a well-established and well-known actor in the global supply chain of ICT hardware components (Lee and Pech 1997; Mathews 1997; Saxenian 2002). In order to upgrade the local ICT industry and build a ubiquitous ICT environment in Taiwan, the Executive Yuan, the government agency that enacts executive functions of the Taiwanese government, announced the fiveyear, $€ 770$ million, national-level M-Taiwan Program in 2005, tied in with the preceding three-year e-Taiwan Program. One goal of the M-Taiwan Program is to build a worldclass wireless broadband access environment as the foundation of mobile services, mobile learning, and even mobile life (WiMAX Forum 2007a).

Figure 1 illustrates a map developed from the central government structure in Taiwan, ${ }^{1}$ which shows key government agencies related to the M-Taiwan Program. Two major units under the Executive Yuan are the Ministry of Economic Affairs (MOEA), the Taiwanese economic and industrial development authority, and the National Communications Commission (NCC), the communications industry regulator.

${ }^{1}$ From the Government Information Office website, http://category.www.gov.tw/Category/ default.aspx? cateitem=gov1\&cateab=onlineformapply (retrieved February 27, 2008). 


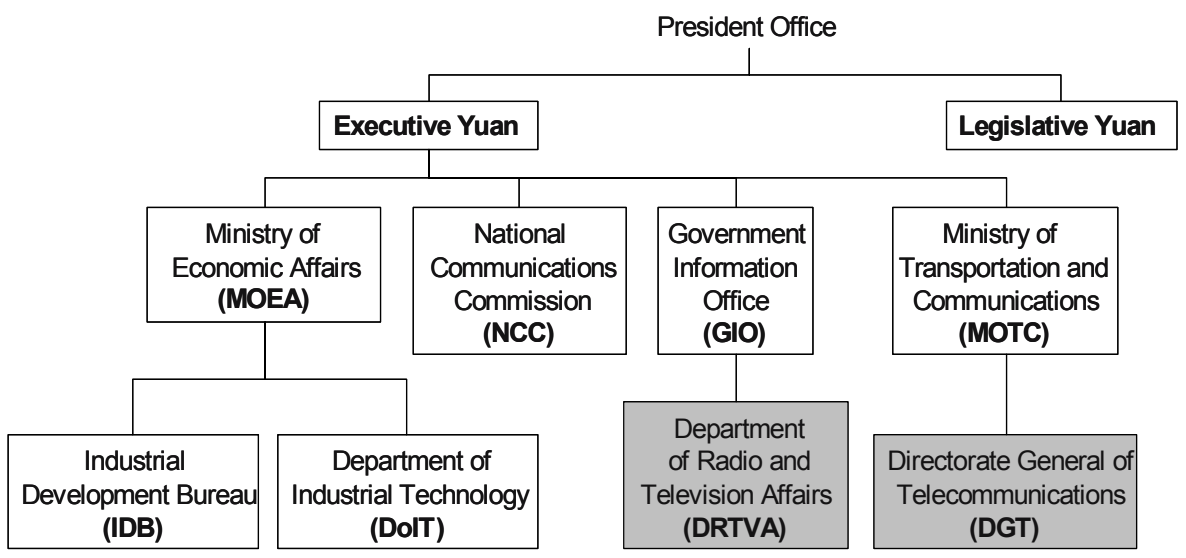

Unit which partial authority was took over by NCC

\section{Figure 1. Key Government Agencies Related to M-Taiwan Program}

The MOEA has been a market accelerator of Taiwanese industries for decades. It has two subunits in charge of ICT industrial affairs. One is the Industrial Development Bureau (IDB), which is responsible for promoting advanced technologies, building close interrelations among industries, and supporting the expansion of ICT industry and its markets. The other is the Department of Industrial Technology (DoIT), which coordinates national ICT research resources, including those from research institutions, universities, and firms, in order to transfer basic R\&D knowledge into innovative applications. However, without good capability to develop advanced technologies through basic research, Taiwan tends to adopt the technology standards of developed countries, resulting in a high patent cost for manufacturing hardware using those standards (e.g., $3 \mathrm{G})$. Moreover, the MOEA tends to pursue short-term results due to political pressure. For example, three ministers of Economic Affairs were replaced during the past four years; thus, the plans sponsored by the MOEA are generally shorter than five years and sometimes reinterpreted widely during the middle of a current plan.

The NCC became operational in February 2006, imitating the Federal Communications Commission (FCC) in the United States. To coordinate spectrum and regulatory issues derived from the competition among a variety of digital platforms across telecommunication, broadcasting, and Internet technologies, the NCC took over authority from the Directorate General of Telecommunications (DGT) and the Department of Radio and Television Affairs (DRTVA), two subunits of existing government agencies in charge of the affairs in the telecommunication and broadcasting industries respectively.

The NCC faced organizational resistance, especially from the Executive Yuan and its spokesman Government Information Office (GIO). One example is that the first set of NCC commissioners is involved in a political rivalry between the Executive Yuan and the Legislative Yuan, the congress of Taiwan, because they are dominated by the two largest political parties respectively. This occurs despite the fact that the NCC is meant to be independent from governmental or political interference, according to the spirit of 
the National Communications Commission Organization Act (NCC Organization Act) approved in November 2005. Yan (2007) provides evidence of this political situation by highlighting three points.

- In February 2006, the Executive Yuan argued that it should propose the list of NCC commissioners because the NCC is under the Executive Yuan. However, the Legislative Yuan argued that the FCC in the United States is an independent government agency, directly responsible to the Congress, so NCC commissioners should be appointed based on the seating percentage of political parties in the Legislative Yuan. In the end, nine commissioners were appointed using the Legislative Yuan's argument.

- In July 2006, the Justices of the Constitutional Court declared this selection violated the Constitution. The commissioners had to resign and be reselected. The commissioners then announced that their selection was legal according to the NCC Organization Act, but they would resign along with the election of Legislative members in January 2008. They also called on an amendment to the NCC Organization Act, which was not settled until December 2007.

- In April 2007, the Executive Yuan declared "Ten Crimes of NCC" based on an internal investigation, including the questioning of five NCC commissioners integrity. Subsequently, the former premier of the Executive Yuan ordered two commissioners to be suspended, leaving seven commissioners to run the system.

Another example of the organizational resistance is that the GIO has continued showing its interests in replacing the NCC. This can be evidenced by two events.

- In June 2007, the head of GIO alleged that the NCC's approval of selling a radio station once owned by the opposition party had abused its authority and benefitted both the radio station and the buyers. The NCC chief commissioner then responded by claiming there was a lack of evidence (China Post 2007; United Daily News 2007a).

- In December 2007, the chief convener of the ruling party suggested that the GIO take over the NCC if the NCC Organization Act was not amended in time. The head of GIO said that the Executive Yuan would consider this possibility (Chu 2007; United Daily News 2007b).

The shifting power of various conflicting institutional groups has influenced the complex and mixed governmental interventions that have affected the initiation and early diffusion of the DVB-H and WiMAX technologies. We turn to these next.

\subsection{Governmental Interventions in DVB-H Technology}

In this and the following section, we use the six types of governmental interventions in King et al.'s framework to analyze how government agencies intervene in the production and diffusion of wireless broadband technologies in Taiwan. The dimensions 
of each intervention are noted by Roman numerals I, II, III, and IV at the end of these intervention statements (see Table 1).

\subsubsection{Knowledge Building}

As mentioned above, the knowledge building of advanced technologies in Taiwan is usually produced through a series of localizing processes. The basic DVB-H technical knowledge was introduced by industrial associations and local firms. As Dr. C. Shih, the director general for Taiwan Digital Television Committee (DTVC) and the chief executive officer (CEO) for DAWN TV Technology Corporation, stated in our interview,

The DTVC has organized yearly business tour groups to visit European digital [or mobile] TV companies since 2004. I'm the first leader of the group. At that moment, Nokia didn't have any mobile multimedia team in Taiwan, but we visited its Finish headquarters and met the vice president directly....Afterwards, DAWN TV began the mobile TV business in Taiwan and received significant technical support from Nokia China and then Nokia Taiwan.... The government sensed the [market] potential of DVB-H technology when we did the first live trial at the Taipei TV \& Film Festival 2005.

This building of localized know-how using DVB-H technology captured the government attention. Afterward, the DoIT sponsored the DVB-H Operation Platform and Business Model Research Project in 2005, the Mobile Video Interactive Application Planning Project in 2006, and the Innovative Service on Mobile TV over DVB-H Research Project in 2007 (I). ${ }^{2}$ However, the budget of each project was less than $€ 100,000$, so the knowhow was not available to the public until three to five years later.

\subsubsection{Knowledge Deployment}

After the industry showed interest in DVB-H technology, various government agencies started to distribute knowledge about DVB-H technology. A number of publications, conferences, and courses have been endorsed or sponsored to foster industrial development, to promote digital multimedia applications, and to train skilled technical employees (I). The main intervention was that the IDB included the issue of DVB-H technology into the last-year High Definition Video Multi-medium Industry Development Five-Year Promotion Program in 2005 and into the last two-year Broadband and Wireless Communications Industry Development Five-Year Promotion Program ${ }^{3}$ in 2006 and 2007. Nevertheless, compared with the respective themes of each program - digital TV and WiMAX technology-DVB-H technology was a minor issue. As a result, no significant budgets or efforts were devoted to the diffusion of DVB-H technology.

${ }^{2}$ From the Department of Industrial Technology website (http://doit.moea.gov.tw; retrieved February 22, 2008.

${ }^{3}$ From the Government Research Bulletin website, http://www.grb.gov.tw (retrieved February $25,2008)$. 


\subsubsection{Subsidy}

Criticized by the industry, the GIO only subsidized one terrestrial TV stations, the Public Television Service Foundation (PTS), the only public TV station in Taiwan (like the BBC in the UK), for its initial DVB-H server-side systems and its interactive or made-for-mobile video content production (IV), even through the subsidization did not go smoothly. In 2005, PTS proposed a $€ 1.35$ million DVB-H subproject, which was included in a $€ 93$ million Two-Year Project of Public Broadcasting Cultural Creation and Digital Television Development (PTS 2006), but the budget was frozen by the Legislative Yuan until May 2007 (RDEC 2007). Facing this biased subsidy structure, the terrestrial TV stations applying for the scant research funding from the DoIT tended to secretly divert partial funding to the procurement of DVB-H facilities.

\subsubsection{Mobilization}

At the beginning, the government encouraged the decentralized actors to think of DVB-H technology in a particular way: fulfilling mobile TV services efficiently. The IDB supported establishing the Mobile TV Alliance, a community spanning the broadcasting and ICT industries, in August 2005 (II) (Lai 2005). In mid-2006, however, NCC announced the Handheld Mobile TV Trial Program and preferred to remain neutral about mobile TV technology. Five trial licenses were released not only to the consortiums using DVB-H technology but also to a consortium using MedioFLO, another competitive digital broadcasting technology. The awareness of DVB-H technology was unfortunately blurred.

\subsubsection{Standard Setting}

It is difficult to determine whether the government has set standards for the diffusion of DVB-H technology. In the Handheld Mobile TV Trial Program, the NCC not only limited the trial areas of the five consortiums (three in northern Taiwan and two in southern Taiwan ) but also asked the consortiums to pass the technical examination within 6 months and to finish consumer trials in no longer than 18 months. Nonetheless, the NCC did not promise that the trial results would result in commercial licenses for mobile TV. Moreover, the spectrum allocation and the numbers of commercial licenses have not been decided yet. This confusion was recorded in our field notes, as the call made by one of the consortiums in the mid-term review seminar of the trial program on April 26, 2007:

The vague policy has become the biggest bottleneck of our trial. Without a timetable and methods of the commercial license releasing, the members in our consortium hesitate to invest further.

\subsubsection{Innovation Directive}

With a long-run argument about whether the mobile TV over DVB-H should be regulated by the Radio and Television Act, which had been authorized by GIO, or the 
Telecommunication ACT, which had been authorized by DGT, no clear innovation directive has been issued. As an interviewee for a terrestrial TV station said,

We have a mother-in-law and a father-in-law [GIO and NCC], and we can't offend either of them.

Although the NCC has proposed the first draft of the Converged Communication Law in order to enhance effective competition in the digital convergence environment, the rivalry between the Executive Yuan and the Legislative Yuan is very likely to delay this act.

In summary, a notable phenomenon in the early diffusion of DVB-H technology is that industrial actions are usually ahead of governmental interventions, resulting in a bottom-up institutionalization process and an unclear governmental plan.

\subsection{Governmental Interventions in WiMAX Technology}

Unlike the diffusion of DVB-H technology, the government has led and even directed the diffusion of WiMAX technology. Organized institutional interventions have been deployed as a top-down strategy according to the $€ 23$ million Taiwan WiMAX Blueprint proposed by the Executive Yuan in 2005, which states

WiMAX technology will be a focus for the future of Taiwan ICT industry and will be a preferred technology option...in the M-Taiwan Program (WiMAX Forum 2007b).

\subsubsection{Knowledge Building}

Supporting the Executive Yuan policy, the DoIT proposed a three-year WiMAX Speed-up Program from January 2006, with an additional and particular $€ 5.8$ million budget allocation. It subsidized some R\&D projects of WiMAX chipsets, base stations, consumer premises equipment (CPEs), and application platforms (e.g., voice over IP, IPTV broadcast, or e-Health), hoping to build a complete WiMAX supply chain in Taiwan (I) (Lin 2006). Although critical WiMAX chipset technology was still held by international companies, a few Taiwanese companies were able to provide WiMAX end-toend solutions at the end of 2007.

\subsubsection{Knowledge Deployment}

To deploy WiMAX knowledge, the Executive Yuan coordinated its subunits' functions. For example, to ensure the supply of WiMAX professionals, the Executive Yuan requested the MOEA to amend the professional training and subsidization measures (I) and the Ministry of Education to review higher education courses (II) respectively (NICI 2007). Moreover, one mission of the last three-year Broadband and Wireless Communications Industry Development Five-Year Promotion Program was to bring international resources in the local ICT industry. As a result, the MOEA signed memorandums of 
understanding (MOU) with eight global companies (Alcatel-Lucent, Intel, Motorola, NEC, Nokia Siemens Networks, Nortel, Sprint-Nextel, and Starent) for the technical cooperation and interoperability testing of WiMAX products (I). The global fourth regulatory certification body (RCB), which can issue Taiwan WiMAX certificates, was established in January 2008 (I) (BV ADT 2008).

\subsubsection{Subsidy}

Under the M-Taiwan Program, a $€ 146$ million M-Taiwan Application Promotion Plan was arranged to subsidize the ICT industrial participants entering the WiMAX market. Performed by the IDB, selected ICT companies aligned with regional governments were subsidized to implement the technical and business trials of "wireless broadband cities" (II) (Lin 2006). The subsidized consortiums were requested to purchase at least 20 percent made-in-Taiwan WiMAX base stations and 80 to 100 percent made-in-Taiwan CPEs (IV) (LANcom Express 2007). The subsidies did attract some participants that had no previous interest in WiMAX technology. As a general manager for a telecom company, which acquired a $€ 5.8$ million subsidy in 2005 and then bid a WiMAX commercial licence in 2007, stated in our interview on August 2005,

WiMAX technology hasn't been mature yet. The price of chips and CPEs are still high.... The standard of $3 \mathrm{G}$ costs many years to complete global roaming.... The biggest problem is where the market [of WiMAX technology] is. The profitable high-speed data service is merely video services, but according to our previous experience, consumers pay on rare occasion.

\subsubsection{Mobilization}

After WiMAX technology was chosen as the focus of the national-level M-Taiwan Program, the government launched numerous awareness campaigns (e.g., Taiwan WiMAX Blueprint and WiMAX Speed-up Program) and promotional events (e.g., 2007 Taipei Summit Asia-Pacific WiMAX Conference and Exhibition and the 2007 WiMAX Forum Taipei Showcase and Conference) (II). Despite the early public confusion over which WiMAX standards were supported, the government successfully built two clearer objectives: (1) assisting local ICT manufacturers to win the overseas orders of WiMAX hardware or solutions, following either the $802.16 \mathrm{~d}$ or the $802.16 \mathrm{e}$ standards; (2) supporting local mobile service providers to build Taiwan into the best test bed of the 802.16e standard in order to attract the favor of international WiMAX companies and to create innovative business models. However, the government did not persuade everyone. In late 2007, the two largest mobile service providers in Taiwan intentionally failed to win the WiMAX commercial licenses with surprising low bidding.

"You may see our conservative attitude towards WiMAX technology from our auction price," the vice president Cliff Lai for Taiwan Mobile Company (TMC) said. "We don't think WiMAX will threaten the fixed network or mobile communication market within two years....After two years, we will take part in the 
next auction when the cost of CPEs should be already down, and TMC can wait based on the advantages of our base station coverage (because residents have protested against new base stations due to possible harmful electromagnetic wave)" (Kuang 2007).

\subsubsection{Standard Setting}

The auction of the six regional WiMAX commercial licenses was finalized in July 2007, after a hazy 2006, when the DGT and the NCC competed against each other for their respective plans of spectrum allocation. According to NCC's final version, WiMAX spectrum is in the 2.5 to $2.69 \mathrm{GHz}$ frequency band, and the duration of the licenses is six years. Six winners are allowed to merge or invest in one another for efficient competition, and the second-run licenses are planned to be issued after two years (III). The related regulations are not ready, although the WiMAX licenses were issued. For example, the import of WiMAX facilities for the infrastructure building must pass some examinations, but the NCC has not decided how to examine facilities from abroad (Chung 2008). Such problems delay the diffusion of WiMAX technology.

\subsubsection{Innovation Directive}

The government used directive interventions to encourage the diffusion of WiMAX technology. In the early stage, the government directly provided practical and profitable opportunities to attract industrial participants using WiMAX technology. In the MTaiwan Application Promotion Plan, 10 regional governments offered diverse industrial participants to implement WiMAX technology for the vision of wireless broadband cities (I). For example, the regional government of Taipei City cooperated with a personal handy phone service (PHS) provider to deploy WiMAX infrastructure and applications (e.g., the Taipei e-BUS service) (Lin 2006). After the WiMAX licenses were issued, the NCC required that license winners who did not cover any single city or county with the WiMAX infrastructure over 70 percent of the population within 18 months return their licenses (III) (Wang 2008).

In summary, governmental interventions in WiMAX technology are more comprehensive and effective than those of DVB-H technology. Nevertheless, the potential competition between WiMAX and DVB-H technologies were unveiled while the WiMAX promotion plan has shifted its focus from infrastructure to applications such as mobile TV or Karaoke over WiMAX since 2007. The key lessons we can learn from this case are discussed next.

\section{KEY LESSONS}

Based on the data presented above, we propose that government agencies have an important and significant influence on the diffusion of wireless broadband technologies through numerous interventions. However, the results are somewhat chaotic and unpredictable because of the constant shuffling and rebuilding of government agencies, the 
competing and cancelling effects of government actions across agencies, the conflict across government units and policies, and broad institutional factors.

\subsection{The Width and Depth of Governmental Interventions}

Table 2 summarizes Taiwanese governmental interventions in the initiation and early diffusion of DVB-H technology and WiMAX technology. Comparing the various governmental interventions and the budgets, we find that the width and depth of the governmental interventions in the diffusion of WiMAX technology are greater than those in the diffusion of DVB-H technology.

The difference has come from the top-down strategy of the WiMAX promotion plan. Supported by a national-level program, huge budgets, and efficient spectrum allocation, the government agencies have helped to speed up the early diffusion of WiMAX technology, in accordance with the common practical belief that a top-down strategy enables the integration of resources across different government agencies. However, our case also reveals how a dynamic institutional context complicates the effects of governmental interventions.

\subsection{The Difficulties of Governmental Restructuring}

Complexity in authorities, programs, and regulations has emerged because nomadic technologies have blurred industrial boundaries. As a result, it is time-consuming to build or to maintain consistent and mutually supporting governmental mechanisms and regulatory effects in the diffusion of complexity technologies, such as nomadic technologies. For example, mobile TV services supported by DVB-H or WiMAX technologies need cooperation among media, telecommunication, and IT industries. However, before the NCC's establishment, the media industry was governed by the GIO, the telecommunication industry was governed by the DGT, and the IT industry was governed

Table 2. Taiwanese Governmental Interventions in the Initiation and Early Diffusion of DVB-H Technology and WiMax Technology (using King et al.'s Framework)

\begin{tabular}{|c|c|c|c|c|}
\hline & \multicolumn{2}{|c|}{ DVB-H } & \multicolumn{2}{|c|}{ WiMAX } \\
\hline & Supply-Push & Demand-Pull & Supply-Push & Demand-Pull \\
\hline Influence & $\begin{array}{l}\text { (1 Knowledge } \\
\text { building } \\
(<€ 100,000) \\
2 \text { Knowledge } \\
\text { deployment }\end{array}$ & 4 Mobilization & $\begin{array}{l}\text { (1 Knowledge } \\
\text { building }(€ 5.8 \mathrm{M}) \\
\text { 2 Knowledge } \\
\text { deployment }\end{array}$ & $\begin{array}{l}\text { 2 Knowledge } \\
\text { deployment } \\
\text { 3 Subsidy } \\
(€ 146 \mathrm{M}) \\
\text { (4 Mobilization }\end{array}$ \\
\hline & & II & & II \\
\hline & III & IV & III & IV \\
\hline Regulation & $\begin{array}{l}\text { (5 Standard } \\
\text { setting) }\end{array}$ & $\begin{array}{l}\text { (3) Subsidy } \\
(€ 1.35 \mathrm{M})\end{array}$ & $\begin{array}{l}\text { (5) Standard setting } \\
6 \text { Innovation } \\
\text { directive }\end{array}$ & (3) Subsidy \\
\hline
\end{tabular}


by the MOEA. After NCC's establishment, the integration has encountered significant reluctance. Another example is that the government, regardless of the discontinuity of related plans and knowledge workers, allocated the DVB-H technology to be aided by the High Definition Video Multi-medium Industry Development Five-Year Promotion Program for the first year and by Broadband and Wireless Communications Industry Development Five-Year Promotion Program for the next two years because it was barely aware of the position of DVB-H technology in the early stage. Similar uncertainty existed in the copious argument of the Converged Communication Law about which part of the regulations should descend from the principle of the Broadcasting and Television Law or that of the Telecommunication Act. These situations reveal that an ambition to rebuild complete and comprehensive governmental and regulatory contexts is very difficult and adds to the complexity and lack of predictability about the form and time to market of nomadic technologies.

\subsection{The Contradiction among Government Agencies}

In addition to the innate difficulties of restructuring governmental agencies and policies in the face of new technology, the long-term interorganizational debate across agencies (like the Legislative Yuan and the NCC against the Executive Yuan, the GIO, and the DGT, in this case) results in an unstable political context. An obvious example in the case is the rivalry between the Legislative Yuan and the Executive Yuan, managed by the two largest opposition political parties. Another illustration is that the first mobile TV over DVB-H consortium had lobbied and convinced the GIO in 2005, but they were told to negotiate with the NCC when they attempted to do a large-scale field trial in 2006. During the first-year struggle between the NCC and the GIO, some members were uncertain whether their efforts again would be in vain and withdrew from the consortium. These contradictions among government agencies tend to frustrate industrial participants and prevent a clear path to the diffusion of technologies because of the uncertainty.

\subsection{Competition between Technologies Enabling Similar Applications}

Although the technical principles of the DVB-H and WiMAX technologies are apparently different, more and more stakeholders, including adopters, investors, and government officers, compare them during the decision-making stages because both of them enable the delivery of mobile TV. Thus, with WiMAX suddenly catching more attention and getting more resources through stronger governmental promotion, including the national programs and media reports, stakeholders felt increasingly confused. As the project manager of a DVB-H consortium said in the interview,

When I invited companies from the other industries to join our group or introduced mobile TV over DVB-H in exhibitions, I was often questioned why consumers need mobile TV over DVB-H when they are having WiMAX services in the near future. 
Moreover, in our cases, the two largest mobile service providers, which have advantages of DVB-H return channels and WiMAX base station deployment, prefer to wait and see the next-generation wireless broadband technologies instead of joining the diffusion of DVB-H and WiMAX technologies now. Such feedback reveals an important issue in government policy making: the potential competition among emerging nomadic technologies that enable similar applications. Governmental intervention in these technologies, especially the complexity of different government agencies with different and sometimes contradictory effects, has resulted in a complex environment, with numerous financial and human resources spent on producing this complexity.

\subsection{ICT Diffusion Influenced by Broad Institutional Factors}

In addition to the political issues, economic or socio-technical factors influence the industrial field-of-play in the diffusion of nomadic technologies. Intel's withdrawal is a clear example. In 2004, Intel announced that WiMAX chips would be integrated into laptops in 2006 and mobile handsets in 2007. At the end of 2006, however, Intel deferred its integration plan to 2007. In late 2007, Intel downgraded WiMAX modules as selective items to its cooperative hardware manufacturers (MOEA 2008). The withdrawal, due to pessimistic global market forecasts, has not only influenced the diffusion of WiMAX technology but also increased the risk of for governmental interventions.

In 2005, Intel signed the first WiMAX MOU with the MOEA in Taiwan. Until 2008, however, Intel hasn't realized its promise to invest a local center for interoperability testing in Taiwan but invested in the Japanese telecom company KDDI, which is shameful to MOEA (Juang 2008).

Therefore, we suggest that various governmental agencies should pay attention to their own and other broad institutional factors in order to increase the comprehensiveness and the flexibility of long-term actions and plans for nomadic technologies.

\section{CONCLUSION}

Institutional theory provides a rich theoretical view for the study of the interplay between contexts and IT artefacts, including governmental influence on the early diffusion of nomadic technologies. Using the key concepts of institutional theory, including King et al.'s framework, we have examined how various Taiwanese government agencies affected the context around the production and diffusion of two wireless broadband technologies, DVB-H and WiMAX. Several conclusions have been drawn from the analysis.

- Governments are able to affect the diffusion of nomadic technologies through their legitimating powers, specific national policies, the allocation of radio frequency spectrum, the implementation of regulations, and the allocation of financial resources. A top-down strategy seems to be beneficial to the width and depth of 
governmental interventions, but the ultimate effects are uncertain because of broad institutional forces.

- Given the industrial blurring of partners involved in mobile TV, a government restructuring is time consuming and difficult, delaying the participants' development of a clear technology and standard, as well as their time to market. To speed up the communication between the agencies responsible for nomadic technologies, a more efficient mechanism is required.

- The political conflicts between government agencies have and will weaken the clear influence of any governmental unit, and increased the uncertainty involved in the production and diffusion of a nomadic technology.

- Nomadic technologies with different technical principles will compete with one another when they enable the same or similar innovative applications. Without comprehensive consideration from an application view, the effects of governmental interventions on technologies might be mutual offset, wasting governmental resources. The key actors that have irreplaceable advantages have a tendency to wait and see.

- In addition to governmental intervention, the diffusion of nomadic technologies is affected by broad institutional factors. Governments should predict and watch for these outside influences in order to respond with changes as quickly as possible.

This paper has some limitations regarding the generalizability of conditions because it discusses a single embedded case in Taiwan. However, as governmental intervention in the initiation and diffusion of ICT technologies is common in many countries, this paper is expected to raise some general insights and questions for the future. In the future, more research is needed in the diffusion of technologies, including nomadic technologies, using in an institutional view, including different institutions, other technologies, and other, different national contexts.

\section{References}

Allen, D., and Wilson, T. D. 2005. "Action, Interaction and the Role of Ambiguity in the Introduction of Mobile Information Systems in a UK Police Force," in Mobile Information Systems, E. Lawrence, B. Pernici, and J. Krogstie (eds.), Boston: Springer, pp. 15-36.

Andersen, K. V., Bjørn-Andersen, N., and Dedrick, J. 2003. "Governance Initiatives Creating a Demand-Driven E-Commerce Approach: The Case of Denmark," The Information Society (19), pp. 95-105.

Avgerou, C. 2000. "IT and Organizational Change: An Institutionalist Perspective," Information Technology \& People (13:4), pp. 234-262.

BV ADT. 2008. "BV ADT is Authorized by NCC and Becomes the First RCB to issue WiMAX Mobile Station Certificate," Bureau Veritas Advance Data Technology, January 23 (http://www.adt.com.tw/english/news_files/2008012301.pdf).

China Post. 2007. "Cabinet Orders Probe of Approval of BCC's Sale Approval," June 28 (http:// www.chinapost.com.tw/taiwan/2007/06/28/113561/Cabinet-orders.htm).

Choudrie, J., and Lee, H. 2004. "Broadband Development in South Korea: Institutional and Cultural Factors,” European Journal of Informational Systems (13), pp. 103-114. 
Chu, J. 2007. “Taking Over NCC—Wishful Thinking by the Ruling Party,” National Policy Foundation, December 18 (http://www.npf.org.tw/particle-3752-1.html, in Chinese).

Chung, H. 2008. "Blank Regulation Influences the Purchase of WiMAX Facilities," DIGITIMES., January 22 (in Chinese).

Damsgaard, J., and Lyytinen, K. 2001. "The Role of Intermediating Institutions in the Diffusion of Electronic Data Interchange (EDI): How Industry Associations Intervened in Denmark, Finland, and Hong Kong," The Information Society (17:3), pp. 195-210.

Damsgaard, J., and Scheepers, R. 1999. "Power, Influence and Intranet Implementation: A Safari of South African Organizations," Information Technology \& People (12:4), pp. 333-358.

Henfridsson, O., and Lindgren, R. 2005. "Multi-Contextuality in Ubiquitous Computing: Investigating the Car Case through Action Research," Information and Organization (15), pp. 95-124.

Ishii, K. 2004. "Internet Use via Mobile Phone in Japan,” Telecommunications Policy (28:1), pp. 43-58.

Juang, Y. 2008. "Intel Failed to Keep Its Word Despite the MOU with the Government," DIGITIMES, February 22 (in Chinese).

King, J. L., Gurbaxani, V., Kraemer, K. L., McFarlan, F. W., Raman, K. S., and Yap, C. S. 1994. "Institutional Factors in Information Technology Innovation," Information Systems Research (5:2), pp. 139-169.

Kling, R., and Scacchi, W. 1982. "The Web of Computing: Computer Technology as Social Organization," Advances in Computers (21), pp. 1-90.

Kuang, W. 2007. "TMC: Watch 3.5G Because WiMAX Won't be a Threat," ZDNet, October 25 (http://www.zdnet.com.tw/news/comm/0,2000085675,20125515,00.htm; in Chinese).

LANcom Express. 2007. "NCC Unveils Local WiMAX License, Upcoming Billions Market Forecasts," September (http://www.lancom.com.tw/Express/news/New75_03.htm).

Lai, W. H. 2005. "Report of Visiting IFA and IBC 2005-Trend of Mobile TV Technologies," December 30 (http://www.pts.org.tw/ rnd/p9/2005/IBC\%209412.pdf; in Chinese).

Lee, C., and Pech, M. 1997. The Taiwan Electronics Industry, Boca Raton, FL: CRC Press.

Lee, H., O'Keefe, R. M., and Yun, K. 2003. " "The Growth of Broadband and Electronic Commerce in South Korea: Contributing Factors," The Information Society (19), pp. 81-93.

Lin, B. 2006. "WiMAX Development and M-Taiwan: Blueprint, M-Taiwan, and Product Development," presentation to the 2006 Taipei Summit: Taiwan-Southeast Asia ICT Forum, June 6 (http://www.nectec.or.th/users/htk/files/20060605-WiMAXinTaiwan. pdf).

Lin, S., and Chiasson M. W. 2007. "Dynamic Approach to Context in Diffusion Research: An Actor Network Theory Study of Mobile-TV Service," in Organizational Dynamics of Technology-Based Innovation: Diversifying the Research Agenda, T. McMaster, D. Wastell, E. Fernely, and J. I. DeGross (eds.), Boston: Springer, 315-330.

Lyytinen K., and Rose, G. M. 2003. "Disruptive Information System Innovation: The Case of Internet Computing," Information Systems Journal (13:4), pp. 301-330.

Lyytinen, K., and Yoo, Y. 2002. "Research Commentary: The Next Wave of Nomadic Computing," Information Systems Research (13:4), pp. 377-388.

Markus, M. L., and Robey, D. 1988. "Information Technology and Organizational Change: Causal Structure in Theory and Research," Management Science (34:5), pp. 583-598.

Mathews, J. 1997. "Silicon Valley of the East: Creating Taiwan's Semiconductor Industry," California Management Review (39:4), pp. 26-54.

MOEA. 2008. "Intel Downgrade WiMAX to One of the Choices in Laptops," Ministry of Economic Affairs, January 5 (http://assist.nat.gov.tw/GIP/wSite/ct?xItem=10415\&ctNode $=23 \& \mathrm{mp}=2$; in Chinese).

Miscione, G. 2007. "Telemedicine in the Upper Amazon: Interplay with Local Health Care Practices," MIS Quarterly (31:2), pp. 403-425.

Montealegre, R. 1999. "Temporal Model of Institutional Interventions for Information Technology Adoption in Less-Developed Countries," Journal of Management Information Systems (16:1), pp. 207-232. 
National Science Council. 2006. Evaluation Results of National Telecommunication Technology Plans (in Chinese).

NICI. 2007. "The Discussion Record of WiMAX Manpower Cultivation and Training," National Information and Communications Initiative Committee, Taiwan, July 4 (http://www.nici. nat.gov.tw/content/application/nici/meeting/guest-cnt-browse.php? cnt id=2478; in Chinese).

Orlikowski, W. J., and Barley, S. R. 2001. "Technology and Institutions: What Can Research on Information Technology and Research on Organizations Learn from Each Other?," MIS Quarterly (25:2), pp. 145-165.

PTS. 2006. "Two-Year Project of Public Broadcasting Cultural Creation and Digital Television Development," Public Television Service Foundation, Taiwan (http://www.pts.org.tw/ $\sim$ web02/2years/plan1.htm; in Chinese).

RDEC. 2007. "Investigation on Two-Year Project of Public Broadcasting Cultural Creation and Digital Television Development," Research, Development and Evaluation Commission, Taiwan (http://www.rdec.gov.tw/public/Attachment/773116425371.doc; in Chinese).

Sawyer, S., Allen, J. P., and Lee, H. 2003. "Broadband and Mobile Opportunities: A Sociotechnical Perspective," Journal of Information Technology (18), pp. 121-136.

Saxenian, A. 2002. "Transnational Communities and the Evolution of Global Production Networks: The Cases of Taiwan, China, and India," Industry and Innovation (37), pp. 1-35.

Scott, W. R. 1995. Institutions and Organizations, Thousand Oaks, CA: Sage Publications.

Silva, L., and Figueroa, E. B. 2002. "Institutional Intervention and the Expansion of ICTs in Latin America: The Case of Chile," Information Technology \& People (15:1), pp. 8-25.

Swanson E. B., and Ramiller, N. C. 1997. "The Organizing Vision in Information Systems Innovation," Organization Science (8:5), pp. 458-474.

Teo H. H., Wei, K. K., and Benbasat, I. 2003. "Predicting Intention to Adopt Interorganizational Linkages: An Institutional Perspective," MIS Quarterly (27:1), pp. 19-49.

Tilson, D., Lyytinen, K., Sørensen, C., and Liebenau, J. 2006. "Coordination of Technology and Diverse-Organizational Actors during Service Innovation: The Case of Wireless Data Services in the United Kingdom," paper presented at the Helsinki Mobility Roundtable, Helsinki, Finland.

United Daily News. 2007a. "The Head of GIO Has No Sense of Propriety," June 28 (in Chinese).

United Daily News. 2007b. "A Whisper that the Executive Yuan Might Take Over NCC," December 16 (in Chinese).

Wang, Y. 2008. "WiMAX Implementation Deferred Because of Expensive Base Station," The Liberty News, March 3 (http://www.libertytimes.com.tw/2008/new/mar/3/today-e4.htm; in Chinese).

WiMAX Forum. 2007a. "M-Taiwan Program A WiMAX Ecosystem," March (http://www. wimaxforum.org/technology/downloads/M_Taiwan_Program.pdf).

WiMAX Forum. 2007b. "M-Taiwan Applications Promotion Program," Taipei Showcase \& Conference website, December (http://www.wimaxforum.org/taipei/m-taiwan).

Yan, J. 2007. "The Competition Between NCC and the Executive Yuan," ETtoday News, April 2 (in Chinese).

Yin, R. K. 1984. Case Study Research: Design and Methods, Newbury Park, CA: Sage Publications.

\section{About the Authors}

Su-Yi Lin is a Ph.D. candidate in the Department of Management Science at Lancaster University. She received her MBA degree from the University of Taipei, and then worked as an industry analyst and a manager in the ICT industry for 10 years. Her research interests include the socio-technical context around Internet and mobile technologies, and the social effects of digital convergence. Su-Yi can be reached at s.lin5@lancaster.ac.uk. 
Mike W. Chiasson, Ph.D., is a senior lecturer in the Department of Management Science at Lancaster University and an Advanced Institute for Management (AIM) Innovation Fellow. Mike's research examines the relationships between institutional contexts and the development and implementation of information systems. His work includes action research, user involvement, IT diffusion, privacy, outsourcing, and social foundations of IS development and use. Mike can be reached atm.chiasson@lancaster.ac.uk. 